This is an Accepted Manuscript of an article published by Taylor \& Francis in Journal of Further and Higher Education on 12 Mar 2020, available online: http://www.tandfonline.com/10.1080/0309877X.2020.1735321.

\title{
Between promises and pitfalls: the impact of mobility on the internationalization of higher education
}

\author{
Gonçalo Paiva Dias ${ }^{1 *}$, Belem Barbosa ${ }^{2}$, Claudia Amaral Santos ${ }^{3}$, Margarida M. Pinheiro ${ }^{4}$, Dora \\ Simões $^{5}$, Sandra Filipe ${ }^{6}$ \\ ${ }^{1}$ Águeda School of Technology and Management (ESTGA), University of Aveiro, and Research Unit on Governance, \\ Competitiveness and Public Policies (GOVCOPP), Águeda, Portugal. Corresponding author: gpd@ua.pt. ORCID: 0000-0002-8599- \\ 3798 . \\ ${ }^{2}$ Higher Institute of Accounting and Administration (ISCA-UA), University of Aveiro, and Research Unit on Governance, \\ Competitiveness and Public Policies (GOVCOPP), Aveiro, Portugal. ORCID: 0000-0002-4057-360X \\ ${ }^{3}$ Higher Institute of Accounting and Administration, (ISCA-UA), University of Aveiro, Research Unit on Governance, \\ Competitiveness and Public Policies (GOVCOPP), and CLLC Languages, Literatures and Cultures Research Centre, Aveiro, \\ Portugal. ORCID: 0000-0003-2630-294X \\ ${ }^{4}$ Higher Institute of Accounting and Administration of the University of Aveiro (ISCA-UA) and Research Centre on Didactics and \\ Technology in Education of Trainers (CIDTFF), Aveiro, Portugal. ORCID: 0000-0001-8027-2214 \\ ${ }^{5}$ Higher Institute of Accounting and Administration (ISCA-UA), University of Aveiro, and DigiMedia - Digital Media and \\ Interaction Research Centre, Aveiro, Portugal. ORCID: 0000-0002-9380-4475 \\ ${ }^{6}$ Higher Institute of Accounting and Administration (ISCA-UA), University of Aveiro, and Research Unit on Governance, \\ Competitiveness and Public Policies (GOVCOPP), Aveiro, Portugal. ORCID: 0000-0003-4159-758X \\ * Corresponding author: Escola Superior de Tecnologia e Gestão de Águeda, Universidade de Aveiro. Apartado 473, 3754 - 909 \\ Águeda, Portugal; Phone: +351 234611 500; E-mail: gpd@ua.pt
}

\begin{abstract}
The study presented in this article aims at understanding the relevance of mobility initiatives to the internationalization efforts of Higher Education Institutions (HEIs). By building upon relevant literature, 17 propositions related to this contribution were identified. Empirical evidence from a concrete case of a European university was then used to evaluate those propositions. Data was collected from individual interviews to 19 outgoing faculty and from focus groups with 32 incoming students, resulting in the identification of the promises and pitfalls of mobility. The study concludes that HEIs must define clear strategies and carefully manage their mobility activities to maximize the potential benefits for internationalization. Based on this main implication, it presents a set of managerial recommendations that may be relevant for those involved in administering or promoting international mobility programmes at universities, governments or international organizations, and for researchers in higher education.
\end{abstract}

Keywords: higher education; internationalization; student mobility; faculty mobility; education; globalization

\section{Introduction}

This article addresses the contribution of faculty and student mobility to the internationalization efforts of Higher Education Institutions (HEIs). The main aim is to discuss to what extent empirical evidence is aligned with theoretical and programmatic expectations, relating the contribution of mobility initiatives to the internationalization of both sending and receiving institutions. The associated research questions are: How does incoming and outgoing mobility of students and faculty impact the internationalization of HEIs? What positive outcomes (promises) can be expected? What associated risks (pitfalls) should be avoided? How can HEIs organize to potentiate positive outcomes and avoid associated risks?

To answer these questions, the theoretical contributions from mobility programmes are identified and established as propositions. These propositions congregate multiple perspectives of analysis, are supported by extant literature and formulated from the point of view of HEIs. Evidence from 
a concrete case of a European University is then used to test the propositions and results are analysed to identify the promises and the pitfalls of mobility. Based on this analysis, the article presents a set of managerial recommendations.

The topic is relevant since the number of international higher education students is growing exponentially and universities around the world are increasingly adopting internationalization strategies. In this context, politicians and other public decision-makers may find the conclusions valuable to inform public policies. Concretely, they can be of use to those involved in administering or promoting international mobility programmes in universities, governments or international organizations, and to researchers in higher education.

In this study, we refer to 'mobility' (international academic mobility) as higher education students and faculty (professors and/or researchers) moving from one institution (sending institution) to another foreign institution (receiving institution) to study, teach or research, for a limited period in time and within the scope of a bilateral or multilateral mobility agreement. Student mobility occurs whilst students are undertaking a degree programme at the sending institution. Faculty mobility does not change the person's affiliation to the sending institution. The term 'outgoing mobility' is used from the viewpoint of the sending institution. The term 'incoming mobility' is used from the viewpoint of the receiving institution.

The remaining of the article is organized in the following way: the second section addresses the internationalization of higher education and raises the propositions on the contribution of mobility to the internationalization of HEIs (theoretical background); the third section presents the case of a European university that was used to test the propositions (methodology, results, and discussion); and the fourth and final section concludes the study (conclusions, implications, limitations, and future work).

\section{The re-internationalization trend and the promises of mobility}

Universities are global institutions. Their aim is to create, retain and disseminate knowledge, and knowledge is global. This is nothing new (Altbach, 2004: 4). Yet, many researchers speak of the internationalization of higher education as a recent trend, mostly because of the substantial changes that are taking place in the face of globalization (Stromquist, 2007). International activities became relevant for all types of institutions and encompass all their main processes systematically. Although not all universities compete internationally, all are influenced by that competition. Therefore, the "re-internationalization" of higher education, as Teichler (2004: 6) names it, justifies being regarded as a new phenomenon.

One characteristic of this new phenomenon is the establishment of international agreements and frameworks in Higher Education. Those range from bilateral agreements to support student and faculty exchange or the mutual recognition of degrees, to more comprehensive and multilateral agreements (Altbach, 2004). The Bologna Process and the European Higher Education Area (EHEA) constitute the best example of the latest. EHEA includes 48 European countries and, in the last two decades, has developed several tools to support the recognition of foreign qualifications and study periods abroad including, for example, the European Credit Transfer and Accumulation System (ECTS), the Diploma Supplement (DS), and the European Standards and Guidelines for Quality Assurance of Higher Education (ESG). This is then complemented with specific European programmes such as the ERASMUS+. Amongst several broadly acknowledged benefits, the programme funds the mobility of individuals and the innovation and exchange of good practices in higher education (Organization for Economic Cooperation and Development, 2017).

Departing from the EHEA core objectives, the first proposition comprises a global assertion on the potential impact of mobility in disseminating key university values such as freedom of expression, autonomy, independent student unions, academic freedom, and free movement of students and staff (The Bologna Process Secretariat, n.d.): 
P1 Faculty and student mobility contributes to the dissemination of key university values

Still building on the European case, the second proposition comprises an assertion on the growing expectations related to the role that education and international mobility should play in promoting global citizenship and common values such as human dignity, freedom, democracy, equality, rule of law and interculturalism, usually associated to the European identity and way of life, namely in face of challenges such as populism, xenophobia, discrimination, and radicalization (Council of the European Union, 2018):

P2 Faculty and student mobility contributes to the dissemination of key international values

Messelink et al. (2015) highlight the potential impact mobility can have on people's attitudes, namely in enhancing intercultural understanding amongst students. Even if the first experience abroad may be stressful, posterior experiences of mobility seem to create a more favorable climate for higher levels of intercultural awareness. Throughout the comparative research of what students acquire in terms of competence development and personal growth, and what they gain by studying in their home country, Jacobone and Moro (2015) believe that studying abroad affects in as much as it influences the self-identity of students. Other works (e.g., Martínez-Usarraldea et al., 2017; Cairns, 2018; Rensburg et al., 2015) also stress the importance of mobility for human development and adaptive capacities.

As underlined by Jacobone and Moro (2015), the importance of getting experience while studying in a different cultural context (acquisition of a second language, residence in a foreign country or intercultural understanding) can give academics and students the opportunity to find themselves in advantaged positions either in academia or in the labour market. Amendola and Restaino (2016) state that the mobility experience is the most important element of interviews for the first job. When studying the impact of mobility on students' competencies, the authors also highlight the ability to socialize with other cultures and improve technical skills as positive repercussions.

In line with this and addressing the specific European mobility context, researchers like Messelink and Thije (2012) introduce the concept of 'European capacity' to define the skills to succeed in dealing with differences and multiple identities. These authors suggest that this capacity allows mobility students to operate effectively in multicultural and multilingual groups. MartínezUsarraldea et al. (2017: 107) also refer to the "widespread perception shared by a variety of agents that this programme promotes the development of capabilities as regards adaptation of participants to different environments, the development of skills suited to the labour market, the increase in opportunities for employment and a broadening in the range of options for life projects". This is fundamental for the individual empowerment of each mobility student.

Mobility is one of the key mechanisms through which internationalization occurs and is perceived as a major asset in terms of identity and professional path (Martínez-Usarraldea et al., 2017; Morley et al., 2018). Universities feel therefore pressured to produce graduates with adequate skills to work in international settings, and need to offer their faculty the tools to implement those practices.

Adding to that, the transfer of knowledge occurs faster and is becoming more frequent and intensive, being fuelled by academic staff mobility programmes, international joint degrees, transnational research projects, and electronic media. Those interactions promote leaps forward in reflective thinking by confronting scholars and researchers with different theories, methodologies, and fields of knowledge (Teichler, 2004; Fava-de-Moraes and Simon, 2000).

Several propositions can be formulated at a personal and institutional level to address these aspects:

P3 Faculty and student mobility contributes to self-identity and personal growth 
P4 Faculty and student mobility contributes to the acquisition of new knowledge

P5 Faculty and student mobility contributes to the dissemination of existing knowledge

P6 Faculty and student mobility promotes the acquisition of skills relevant to work in international settings

Another significant characteristic of the so-called re-internationalization is the pressure for universities to produce graduates with adequate skills to work in international settings. This is a consequence of the growing demand for employability of university graduates (Neave, 2002) and the importance of knowledge for the new world economy (Altbach, 1998). In this global society, these qualifications include knowledge of other cultures, intercultural competencies, and foreign language proficiency, just to name a few. International student mobility and internationalization at home are common approaches to tackle these needs (Leask, 2009).

Besides this positive cultural enhancement, several authors (e.g., Jacobone and Moro, 2015) mention foreign language proficiency as one of the highest outcomes of mobility. Llurda et al. (2016) together with Cairns (2018) feel that the use of a different language (mainly English) while abroad not only promotes students' confidence in the practical use of a foreign language but also strengthens the enthusiasm to continue learning it. This aspect of mobility is becoming more visible with the adoption of English as an instruction language in many HEIs academic offers.

The opportunities mobility can provide to individuals, faculty, and students affect HEIs positioning directly. Messelink et al. (2015) point out that the impact of mobility programmes can be enhanced not only by institutional support but also by integrating intercultural learning in the curriculum through the development of intercultural teaching resources. In line with Altbach (2004), practices such as institutional cooperation, and strategies such as internationalization at home could benefit from regular incoming and outgoing mobility initiatives. Also, the mobility of faculty and students might potentially foster new learning and teaching practices.

The propositions associated with these assumptions could, therefore, be postulated as:

P7 Faculty and student mobility contributes to the adoption of English as an instruction language

P8 Faculty and student mobility facilitates internationalization at home strategies

P9 Faculty mobility contributes to the adoption of innovative educational practices

Within this environment, favourable conditions could broaden institutional cooperation. One of the most outstanding opportunities would be the fact that faculty mobility can contribute to the transfer of knowledge (thus further justifying P4 and P5). Moreover, and in line with de Wit (2011), globalization, competition, and market processes have reinforced the implementation of strategic partnerships. Martínez-Usarraldea et al. (2017:107) consider that the Erasmus programme, for example, can be seen as "a strategic platform for the promotion of human development" and promises to continue to play a great role in terms of ties of cooperation. By allowing researchers to meet physically and share their views and research objectives, it can help to establish international joint research projects and joint degrees.

Considering the relevance mobility can have on the development of those aspects, and adding to P4, P5, P8, and P9 above, the propositions would be:

P10 Faculty mobility favours the establishment of joint research projects

P11 Faculty mobility contributes to the establishment of joint degrees and other forms of international curricula 
A third relevant characteristic of the re-internationalization is associated with the emergence of a global marketplace for students and scholars, with large numbers of students, scholars and scientists migrating or traveling abroad temporarily for learning, conducting research and teaching (Altbach, 2004). These flows of students and scholars are very asymmetrical, with some countries and even entire regions of the globe being primarily exporters and others primarily importers (Marginson, 2006; Harman, 2004). In consequence, the world market for higher education is segmented, ranging from a restrict group of world elite universities to many local universities (Marginson, 2006). World elite universities are typically characterized by their research capacity, prestige, ability to attract talent worldwide, and the use of the English language. Local universities are typically teaching-focused institutions supported by local demand. This segmentation is also the consequence of the huge disparities in funding between different countries and, at a national level, by the adoption of performance-based funding that concentrates resources in some institutions to the detriment of others, influencing the ability to compete both nationally and internationally (Teichler, 2004).

Building on this, mobility programmes can impact on future decisions concerning where to study or apply for an academic, research or professional position. As stated by several authors (e.g., Bauder 2015; Martínez-Usarraldea et al. 2017), students and faculty participating in mobility initiatives may have the advantage of transferring knowledge as they move from one country to another. Mobility has therefore been addressed as a path for acquisition, retention, and spreading of information and knowledge, encouraging flexibility and adaptation to several environments. Thus, one of the central issues seems to be the discussion on "higher education institutions and their capabilities to create conditions in which international students - like domestic students feel a strong sense of efficacy in influencing the university practices as well as a sense of belonging to their university and university communities". (Klemencic Žnidaršič et al., 2017:931). Brown et al. (2016) share these same ideas and believe that HEIs should act as a role model in the way they integrate the knowledge of mobility students and faculty.

This data, as Klemenčič et al. (2017) state, is extremely valuable to HEIs. The dimension of mobility experiences in higher education has made it possible to compare educational processes, learning environments and living conditions (Klemenčič et al., 2017; Graf et al., 2017), contributing with new insights to quality procedures. The authors stress that mobility students have a unique positioning in the receiving and sending institutions. Their role as information providers has been underestimated, namely regarding the quality of educational practices and ideas on how to enhance students' experience. Researchers in higher education could benefit from these inputs, improving educational practices and learning environments.

The challenges facing HEIs in this respect and the contribution that mobility can have to the brain drain effect on sending countries (Gribble, 2008) led to the formulation of the following propositions:

P12 Faculty and student mobility contributes to raising talent

P13 Faculty and student mobility contributes to losing talent

Regarding mobility experiences and their impact on HEIs market segmentation and competitiveness, the findings of Bañegil-Palacios and Sánchez-Hernández (2018) point out that experiential marketing is a key element for HEIs sustainability. The authors underline that HEIs should be more attentive to the needs of their incoming students. Similarly, Wen et al. (2016) state that the major challenges for the competitiveness of HEIs in the internationalization of their curricula are English resources, student-faculty interaction on campus, and socio-cultural adjustments. Other relevant factors are the establishment of ties of cooperation (MartínezUsarraldea et al.,2017). These shreds of evidence allude to our previous propositions and highlight once again the importance of mobility agreements to improve HEIs competitiveness and their impact on the segmentation of the higher education market. 
As previously discussed, international mobility occurs in a much-segmented higher education market. It is therefore expectable that this segmentation impacts mobility fluxes. On the one hand, it seems reasonable that the ability to offer exchange programmes with other universities, namely world-leading ones, can foster attractiveness. On the other, it can also be expected that the status of a university (or its position in the rankings, for example) influences the partner institutions with which it establishes mobility agreements, consequently reinforcing the segmentation of the world market for higher education.

Considering this, we propose:

P14 Mobility agreements with the best universities improve the competitiveness of the institution

P15 Mobility agreements reinforce the segmentation of the world market for higher education

Taking into consideration that opinions on mobility experiences are shared with others and that knowing good experiences can help to build trust, our last set of propositions is related to the way participants in mobility programmes may influence their peers.

Reports on the positive effects of mobility on students have been documented through a variety of channels (Klemenčič et al., 2017). The research of Bauder (2015), for example, explores the activities of international doctoral students to conclude that trust, reciprocity, and solidarity have a key role in transnational friendship networks. However, and as Klemencic et al. (2017:926) state, there is still a gap in what regards the comparison of "the quality of education practices, learning environments and student life conditions between their home and host institutions". While studying in another cultural context abroad, students unsurprisingly find themselves comparing practices, methodologies, learning and teaching environments or life conditions with the ones that prevail at their home institutions. The same happens with faculty that experience mobility.

Because of this, students and faculty develop considerations on the similarities or differences between the two contexts and almost inevitably provide advice and suggestions. Nevertheless, Brooks (2018) underlines that although policymakers state that mobility programmes promote a broad set of similarities among students, there are significant differences between the various HEIs within the same country and across countries. And, if a participant in a mobility programme does not find an institutional space to share insights on the experience, the first option to deal with that new situation is normally to talk either with their peers or other acquaintances. Faculty face the same situation before, during and after mobility, conveying feedback on the experience in multiple ways.

In light of these reflections, two last propositions are formulated:

P16 Faculty mobility contributes to foster students' and other faculty mobility

P17 Student mobility contributes to foster faculty and other students' mobility

\section{Evidence from the field}

To further explore the 17 propositions presented in the previous sections, this study adopted a qualitative approach widely used in social sciences (Marczyk et al., 2017), taking into consideration its ability to explore behaviour, attitudes, and opinions. Furthermore, literature in education presents several indicators suggesting particular adequacy of the qualitative methodology to study academic experiences of mobility and internationalization (e.g., Morley et al., 2018; Bedenlier and Zawacki-Richter, 2015). Two complementary qualitative research studies were then conducted, one with faculty (professors and researchers) and the other with students. All participants had mobility experience at one Portuguese university. According to 
Creswell (2013), the collection of primary data is an important part of the research and contributes to its success. Given that faculty have more maturity and autonomy than students to communicate freely about their mobility experiences, the data collection of faculty testimonials was done individually. Students were gathered in small groups. The first study comprised unstructured phenomenological interviews with a convenience sample of 19 outgoing faculty, while the second study comprised focus groups with a convenience sample of 32 incoming students. Data was collected between December 2016 and March 2017.

\subsection{Samples from research studies}

Regarding study 1 , from over 800 active faculty of the university, 107 were identified as having prior mobility experience in the period 2009-2016. Of these, 8 were classified as participants with an outstanding mobility experience, considering that they had accomplished three or more mobility experiences, and 42 had had only one mobility experience. A total of 27 randomly chosen faculty were invited to take part, and 19 accepted by providing informed consent. The participants' characteristics are presented in Table 1.

Table 1-Faculty sample characterization (study 1)

\begin{tabular}{lccc}
\hline Participant & Gender & Seniority & $\begin{array}{c}\text { Number of mobility } \\
\text { initiatives }\end{array}$ \\
\hline Faculty01 & female & Intermediate & 4 \\
Faculty02 & female & Senior & 3 \\
Faculty03 & male & Senior & 3 \\
Faculty04 & female & Intermediate & 3 \\
Faculty05 & male & Intermediate & 4 \\
Faculty06 & female & Intermediate & 1 \\
Faculty07 & male & Intermediate & 1 \\
Faculty08 & male & Junior & 1 \\
Faculty09 & female & Intermediate & 1 \\
Faculty10 & female & Senior & 1 \\
Faculty11 & male & Senior & 1 \\
Faculty12 & female & Senior & 1 \\
Faculty13 & female & Senior & 2 \\
Faculty14 & male & Intermediate & 1 \\
Faculty15 & female & Junior & 1 \\
Faculty16 & male & Junior & 1 \\
Faculty17 & female & Junior & 1 \\
Faculty18 & male & Intermediate & 1 \\
Faculty19 & male & Senior & 1 \\
\hline & & &
\end{tabular}

As mentioned, phenomenological interviews were conducted with faculty. It is an inductive methodology guided by a central question. The aim is to identify a specific phenomenon to obtain a comprehensive description and provide the basis for a reflective analysis of the researcher (Giorgi, 1997). This method emphasizes the interviewees' observations when they recount their experiences, contributing as a support to capture meaning "from the inside" (Osborne, 1994). In this sense, interviewees were first asked to share their personal experience with mobility. Following the narratives, the interviewer asked for further detail, examples, and opinions on the relevant topics that were discussed, keeping control over the conversation to the minimum. Interviews were conducted in Portuguese and were audio-recorded with the agreement of all 
participants, reaching an average of 47 minutes. Content analysis was performed to identify themes and categories that emanated from the spontaneous narratives of the participants. Data saturation was verified at the $15^{\text {th }}$ interview, confirming that the sample dimension $(n=19)$ was adequate. Selected transcripts were translated to English in order to support international publication.

Concerning study 2 , the option was to define a convenience sample comprising six focus groups (FG) with 32 incoming students in the Fall/Winter semester 2016 at the same university. According to Marczyk et al., (2017), focus groups are formally structured groups of individuals brought together to discuss a topic or several topics, allowing for interactions between the researcher, the participants, and among the participants themselves. Groups were organized to provide diversity regarding gender, age, the continent of origin, and prior experience in mobility. As shown in Table 2, FG1 and FG6 comprised only females, FG2 and FG4 had only Spanish language natives, FG3 was composed of the oldest participants in this study, and FG1 and FG4 included students in their first mobility experience.

Table 2-Student sample characterization (study 2)

\begin{tabular}{ccccccc}
\hline $\begin{array}{c}\text { Focus } \\
\text { group }\end{array}$ & $\begin{array}{c}\text { Number of } \\
\text { participants }\end{array}$ & Gender & Age & Origin & $\begin{array}{c}\text { Prior } \\
\text { mobility } \\
\text { experience }\end{array}$ & Language \\
\hline FG1 & 6 & Female & $21-23$ & Europe & no & English \\
FG2 & 4 & $\begin{array}{c}\text { Male and } \\
\text { Female } \\
\text { Male and } \\
\text { Female } \\
\text { FG3 }\end{array}$ & $21-22$ & $\begin{array}{c}\text { Europe and } \\
\text { South America }\end{array}$ & yes and no & Spanish \\
FG4 & 5 & $\begin{array}{c}\text { Male and } \\
\text { Female } \\
\text { Male and } \\
\text { Female }\end{array}$ & $23-24$ & Europe and Asia & yes and no & English \\
FG5 & 6 & Europe & Europe & yes and no & English \\
FG6 & 6 & Female & $21-28$ & $\begin{array}{c}\text { Europe and } \\
\text { South America }\end{array}$ & yes and no & English \\
\hline
\end{tabular}

The organization of the focus groups interviews was structured around three topics: (i) What do mobility students learn during their mobility experience that otherwise could not have learned?; (ii) How valuable is the mobility experience expected to be for their future careers?; and (iii) What new skills do mobility students develop?. Similarly to research study 1 , all interviews were audiorecorded and transcribed, and content analysis was also performed to identify themes and categories that emerged from the focus groups. Data saturation was verified at the $4^{\text {th }}$ focus group. FG1, FG3, FG5 and FG6 were conducted in English. FG2 and FG4 were conducted mainly in Portuguese, resorting to Spanish whenever necessary. Selected transcripts from FG2 and FG4 were translated to English in order to support international publication.

In both studies, ethical principles applicable to the research were shared with the participants, who signed an informed consent authorizing the recording, transcription, and use of the data for scientific purposes. The ethical principles included privacy, confidentiality and voluntary nature of the participation, as well as full information on the research and data collection.

\subsection{Results}

Mobility was portrayed as an exciting, demanding, and out of comfort zone experience by both faculty and students. All participants described being proud, feeling accomplished and belonging 
to a restricted group of elected: the ones who dared, tried, and did it. Faculty felt like ambassadors of their university during mobility. They stressed the importance of presenting institutional videos and other materials, encouraging discussion about home university characteristics, positioning, and values. Still, the main goal of these presentations was to attract international students and enrolments, as Faculty 1, 2 and 6 express:

Another very important thing that usually accompanies my lectures [is that] I begin [...] or I finish talking about the University of Aveiro. [...] I show the University of Aveiro and I do promotion and [...] often the students say they don't remember exactly what the teacher said, but they remember that it was from Portugal... So, these things stay in our memory, they want to know a little more about where you come from, and I always do this introduction. Of the University of Aveiro, of Portugal itself, I speak of our architects, Siza Vieira, Souto Moura...

I think this is the top, this is really that great result we can have, to show our university in such a way that a student then wants to come back to do a doctorate.

Yes, because nowadays, one of the factors that is also critical to the university is the attraction of Erasmus students, foreign students and, therefore, if one is familiar enough with his institution, it may bring some outcomes. If you don't try, you can't get it.

Students did not consider themselves as their university ambassadors, but they frequently compared receiving and sending institutions, namely in terms of teaching-learning strategies and life in the different campuses. Hence, this study provides some evidence of student and faculty mobility contributing to the dissemination of key university values stated in proposition P1, particularly freedom of movement and the intrinsic internationalization in student and professional lives. It is particularly evident that there are no formal strategies for value dissemination and that it falls far behind its potential. The dissemination of key international values such as free movement, interculturalism, and sense of community is much more evident, particularly among students. In all discussions held, students were excited about being global citizens, stressing the differences and many similarities amongst their foreign peers, and their overall pleasure in knowing other cultures and people. A student participant in focus group FG3 illustrates this:

One of the surprises was people I met from other countries, and I found many things very similar. We can communicate and talk about everything and we have similar points of view on things I thought were only applied to my country and that everyone else would think about it differently. But it's not the case, so it surprised me a lot; besides, we establish great friendships with students from other nationalities.

The interviewed faculty also shared these perspectives, hence partially corroborating proposition $\mathbf{P 2}$ on the dissemination of key international values. Indeed, the relevance of mobilities for intercultural communication stood out in the interviews, namely by Faculty 14:

[what I found in the host country] cannot be compared [to Portugal]. (...) it was a very important experience, firstly because it's really a different culture. (...) It was interesting to understand how a subject [such as the one I lectured] was interpreted in such a heterogeneous society. (...) We always have some kind of prejudice, good or bad, an idea of the country and its culture; sometimes it's bad, in the sense that it's totally biased, but to go and testify, confirm or realize that we were completely mistaken is something we all should do... it's mandatory.

The understanding of others' culture aspect was often connected with identity. Students said that mobility helped them recognize the characteristics of their own culture, both because of the need to explain who they are to their foreign peers and because of living abroad and hearing about their peers' realities. Students who took part in this study were also very clear about how important the 
mobility experience was for them in terms of self-awareness, to know their strengths and personality, and to develop soft skills such as self-confidence, autonomy, and resilience. They defined mobility as a unique opportunity to grow as a person. For many of the faculty participating in this study this was also the first time they had to teach in a different cultural context, and, for some, the first time in a different language. Despite the short duration of mobility (usually one week), faculty participants stressed how enriching the experience was professionally and personally, impacting how they assess work and themselves. Faculty 8 and 18, stressed:

I feel I should have done it earlier, I think so. [...] I feel the experience of getting through this resistance $[\ldots]$ is enriching and changes us.

It also has one component, but it's more in another sense, [and it was] allowing contact with different worlds, different people, different cultures, etc. I think this is essential, even from the point of view of the profession.

Being unanimous amongst participants that the mobility experience contributes to self-awareness, our findings strongly corroborate proposition $\mathbf{P 3}$ on self-identity and personal growth.

Both study 1 and 2 provide some support to the propositions regarding the acquisition of new knowledge (P4) and dissemination of existing knowledge (P5), despite evidencing that mobility often fails to contribute to the acquisition and dissemination of scientific and academic knowledge. Faculty often teach some hours and normally use part of those lectures to present their recent work and share their particular expertise. Still, many faculty participants commented on their frustration regarding disseminating their expertise during mobility, as it does not generate enthusiasm from the audience, as expressed by Faculty 3 and 1:

[I] went there and lectured, I don't know, a paper or something. People are there, they are listening ... After, the feedback was often frustrating for me because I was talking about my doctorate [and it] was often just for me and for the supervisor and half a dozen people; [I had] to convert it into normal language so people could understand (...) it's very heavy, and even at the master's level, it doesn't work.

The first time I went it was by the book and I had to give eight hours of classes and it was decided a kind of workshop I lectured over a whole day. In the morning it was the theoretical part with three hours, and then part of the afternoon was the practical one. This was at an institute that was part of the university. And there were only a handful of people in this workshop. This was in my area of research. [...] They liked it, but I think they were being polite, basically. No one worked in that area, the teachers didn't work in that area, and it was more like a "great, that's great" kind of thing.

As mentioned by faculty, the setting in which the mobility occurs is not as favourable for scientific discussion as, for instance, conferences, and although people politely attend workshops and praise them (Faculty 1), there is usually no further interest. Regarding the acquisition of knowledge, the emphasis was mainly on intercultural awareness. Worth mentioning are also best practices and alternative teaching methodologies, as well as research topics and practices used by their peers at the receiving institution, at least for the faculty who associated this goal with the mobility initiative. For students, the dissemination of knowledge is most often limited to informal conversations with peers about culture-related topics, as their international background is usually disregarded in class.

Faculty and students unanimously recognized that during mobility they develop soft skills that enable them to study and work in international settings. Delving into their expectations regarding future professional careers, students hoped that their mobility experience would have a positive impact on their job opportunities. In particular, students mentioned the importance of soft skills to work in multicultural teams, multinational companies, and deal with business internationalization challenges, as explained by three Students participating in focus group FG2: 
I've learned how to manage on my own and make myself understood by others, even if you have a language barrier and [need to] try harder to understand other people. I've learned to be alone in a totally different place and be happy. I've learned to admire different things from different cultures.

Knowing other languages opens new job opportunities; for instance, learning Portuguese can be a plus not only when working with Portugal but with other countries that speak Portuguese as well; also, the international experience is something that companies value a lot, because mobility enables the development of different skills that probably other job candidates don't have, so my international experience will be particularly useful for my professional career.

Exactly, with an international experience you develop skills you cannot develop if you stay in the same place. The same goes to managing money, managing time, making yourself understood, socializing with other cultures.

These findings fully corroborate proposition P6 on the acquisition of skills for international working environments. Some participants used mobility as a trial for a future international career, as they admitted they intend to work in a foreign country, and that now they feel more confident and able to do it. Others stressed the importance of being in specific countries, getting to know foreign languages and cultures, and hence being better qualified to deal with their own culture and work with citizens of their own country.

We observed partial corroboration of proposition $\mathbf{P 7}$ on the contribution of mobility to the adoption of English as an instruction language. Faculty participants underlined that mobility is important to attempt to teach in English and deal with a multicultural class. This was for instance the case of Faculty 8 :

[to teach in English] was perhaps one of my greatest fears. It's not the same talking for 15 minutes in a conference or 3 hours in a row in the classroom. And yes, I was a little scared... 15 minutes we can almost know by heart and just spit it out, but 3 hours is impossible. So I was a little scared, but that does not prevent you from taking the risk. Here I don't teach in English. I'd like to start. The Erasmus experience was also a kind of test to start lecturing in English. (...) I want to [lecture a subject in English]. I've started this week and tried to negotiate with the students, but the resistance was massive. So massive that I postponed the idea for another year because they totally reject having a subject in English, and I, also because of other limitations, ended up accepting that fact. But I hope it's the last time in Portuguese.

While there is a recognition that English contributes to attract mobility students and other type of international students to classes, only a few participants from study 1 reported using English as the main teaching language at their courses.

Students recognize that they contact mostly with other mobility and international students. Thus, there is no corroboration of proposition $\mathbf{P 8}$ on the role mobility might have in facilitating internationalization at home strategies. The actual impact will depend on the type of class international students enrol in, namely having the opportunity to work in groups with nationals, making presentations of case studies or sharing their countries' realities with the class, which, according to these results, does not happen often.

Results from faculty data show that, concerning the positive role mobility could have on the adoption of innovative educational practices (P9), the impact was often very limited, even though one goal for their mobility experiences was to get to know the receiving institution's best practices. Participants reported that they usually learned about those practices during informal meetings, and most placed more emphasis on understanding research and internationalization practices, leaving teaching-learning strategies somewhat neglected. Moreover, they recognized that the impact of their mobility experience in the classroom afterwards is minimal, in part because of the 
lack of flexibility of the courses. The few faculty participants that undoubtedly stressed the impact on the classroom, referred to an indirect impact, such as "the way to see the world" and to approach it, which can markedly affect "how we teach" and "how we deal with problems and persons". Thus, proposition $\mathbf{P 9}$ on faculty mobility contributing to the adoption of innovative educational practices was not supported.

On the contrary, the establishment of joint research projects suggested for proposition P10 was corroborated and recognized by some faculty as their main aim for participating in mobility initiatives. This was particularly evident with repeated mobility experiences. Amongst those with less experience, it was clear that they aimed at finding research partners for future international collaboration, but explained that these collaborations usually take time to develop. Strategies adopted by participants often involved showcasing their work and inviting teachers and especially $\mathrm{PhD}$ students to contact or visit them back. Hence, mobility was portrayed as prospective and used for (trying to) start research collaboration. Many of the participants started taking part in mobility programmes with no prior experience in international research collaboration, putting high hopes and effort on this venture. Contrastingly, faculty with prior international research collaboration often applied for mobility to visit their partners' universities, and included working together on current and future projects. In fact, successful narratives were mostly associated with $\mathrm{PhD}$ thesis supervision and continuous interactions with the same interlocutors, either because of repeated mobility initiatives or prior contacts beyond mobility (e.g., prior joint research projects, meeting at conferences, having worked or studied together). An answer from Faculty 19 illustrates this:

Yes, they are people who know my research. It's usually through research. And so, in this regard, they suggested that I could teach a course more closely linked to my research for master and also undergraduate students, on a more specific topic to which they rarely have a lecturer.

So, this study confirmed that, although faculty mobility intends to establish joint research projects, it is also clear that the efficacy of such efforts demands (i) a well-established strategy with perfect matching of research topics and desire for a new collaboration, and mostly (ii) a continuous contact by either repeated participation in mobility activities or alternative joint efforts.

Apart from the already mentioned international research projects, many participants from study 1 identified exploring the possibility of joint degrees as an essential objective of their mobility, showing a concern with the institutional goal of their home university and an ambition to be associated with wider teaching projects. Faculty 6 said:

[It was] in an attempt to talk to someone about that possibility (...) To have masters with other institutions was a hot topic at the time, but in fact, there was no followup.

Although none of the participants was able to succeed in the establishment of joint projects at the time of the interview, several shared their current efforts toward that goal, especially faculty with management responsibilities at home university, as it was the case of Faculty 6 who was director of a Master Programme and a member of a university department management council. These facts provide empirical support to proposition P11, which suggests that mobility contributes to the establishment of joint degrees and other forms of international curricula.

Another outstanding aspect is the potential contribution of mobility to propositions P12 (raising talent) and P13 (losing talent), an issue that was evident in study 1 with faculty participants. Some of the faculty with more experience in mobility considered that the number of mobility students they had attracted to their home university was a clear success indicator of their own mobility initiatives. This was confirmed by future enrolment of international students. Regarding students, there was clear evidence that mobility contributes to losing talent. Students often discussed their intentions to keep on studying abroad and also to work abroad, but not necessarily in the countries 
that hosted them during mobility. They often see mobility as a trial experience for living/studying/working abroad, and their development as global citizens. Still, they recognized the value of their experiences in the receiving country, expecting it would facilitate, for instance, working in international companies in their home countries. This is explicit in focus groups FG2 and FG3:

We live in a globalized world, increasingly globalized, increasingly open, and these skills are mandatory in multinational companies; and so, for those who want to work there, knowing how to deal with people from different countries, knowing how to get around, stepping out of one's comfort zone, learn by yourself ... these skills will be very useful to me.

I will seriously consider working abroad after Erasmus... Before living here, I hadn't thought about it, but now it seems to be much easier for me.

So, faculty mobility is shown as able to raise talent, while student mobility often contributes to lose talent. Hence, this study partially corroborates propositions P12 and P13.

Some findings on the competitiveness of HEIs and the segmentation of higher education's world market seem to be of particular relevance. Faculty participants often mentioned the desire to visit the best universities in their scientific area. Still, most times that is not possible, since they must choose a university that has a mobility agreement with their institution. For example, Faculty 4 mentioned that, from the list of agreements, she normally selects the most important universities in her field. Therefore, there is an attempt to contact universities with a prior mobility agreement or to use personal contacts (e.g., international research contacts) to break that rule.

It can be then confirmed that the data collected on proposition P14 on the improvement of HEIs competitiveness through mobility is partly corroborated. In fact, a mobility experience at the best universities had to be kept in the wish list for most of the participants in this study. One faculty that shared his opinion on this matter was Faculty 11, who portrayed that, in the case of his department, collaboration with the best universities in the field had a notorious impact on developing innovative educational offers (at graduation and post-graduation levels) and even on discussing and contributing to local social issues. Still, this was the case of an international research collaboration going on for decades, and because of the antecedents, it was only natural that the mobility experiences were directed to the universities this faculty had a long relationship with. These results corroborate proposition P15, as it was clear the reinforcement of higher education segmentation.

Our final remarks will be dedicated to the analysis of propositions P16 and P17 concerning the influence faculty and students can have on their peers. As previously mentioned, faculty assumed an important role in encouraging student mobility, as they shared their experiences and contacts with their home students, and often helped incoming students both before and during their stay. Some participants such as Faculty 2 and Faculty 4 stressed that they applied for mobility during the period they were mobility coordinators. Their purpose was primarily to observe the physical and social environment of their partner institutions to better inform candidates and incite them to try mobility. Interestingly, most faculty participants mentioned that they did not talk much about it with their peers upon returning, only when asked informally for opinion and information by those considering participating in a mobility experience. From the interviews to faculty, there seems to be no consistent procedure of sharing experiences with peers, advising on best strategies for first or repeated mobility initiatives. Thus, we found mixed results regarding proposition P16, as there was evidence of faculty mobility contributing to foster student mobility (both incoming and outgoing), but not a very clear impact on other faculty mobility. Quite the contrary, faculty often mentioned that the ones participating in mobility programmes are "always the same", sometimes even ignoring other colleagues in the same department with similar experiences. 
Other students also encourage student mobility. Incoming students create bonds and invite their national peers to visit them. Moreover, they acknowledge that expressing their enthusiasm and benefits from mobility will indirectly influence their peers to follow their initiative. And, contrary to faculty, they share their experience with their home peers during and after the mobility. Hence, this study partly corroborates proposition P17. Our data does not support students' influence on faculty mobility.

\section{Pitfalls and their implications}

In this article we analysed the impact of mobility activities on the internationalization of higher education. Based on our results, some outcomes are straightforward: it can be expected that mobility will generally contribute to disseminate global citizenship and interculturalism and to promote self-awareness and personal growth; that outgoing faculty mobility will contribute to raising talent (by attracting foreign students) and development of joint research projects; that student mobility will contribute to the acquisition of skills relevant to work in international settings; and that student and faculty mobility will contribute to foster other students' mobility. These are solid mobility promises. Others need clear strategies and careful management to become effective: dissemination of key university values, dissemination and acquisition of knowledge, adoption of innovative educational practices, development of internationalization at home strategies, and establishment of joint degrees and other forms of international curricula. But besides promises, two very relevant pitfalls need attention: outgoing student mobility may end up contributing to losing talent and mobility agreements may fail to build cooperation between HEIs and therefore may contribute to perpetuating the gap between segments of the world market for higher education. Those are manifestations of the tension between the competition and cooperation paradigms in the internationalization of higher education, as defined by van der Wende (2001). These conclusions are based on a coherent set of propositions on the contribution of mobility to the internationalization of higher education. The propositions were grounded in the extant literature, validated empirically, and constitute the main theoretical contribution of this article.

The most important implication of the study is that HEIs have to define clear strategies and carefully manage their mobility activities to maximize the potential benefits and avoid the common pitfalls of internationalization. In line with de Wit (2011), internationalization in higher education should adopt a more organic process-based approach, aimed at a better quality of education and competencies of staff and students. As observed by Knight (2011), more attention should be devoted to the processes involved in organizational strategies to promote internationalization.

Based on our conclusions, this general implication can be translated into a set of managerial recommendations for HEIs:

- Mobility partners should be strategically selected (and balanced) to achieve different but complementary objectives: (i) acquisition of new knowledge, adoption of innovative educational practices and placement of the institution in upper segments of the world market for higher education; (ii) raising of international talent, and dissemination of knowledge and key university values.

- Faculty mobility should be carefully planned to maximize its full potential in terms of the dissemination of existent knowledge, appropriation of new knowledge and establishment of joint research projects and joint degrees, taking into consideration that good matching of research interests and continuity of contacts is very relevant for these purposes;

- Clear strategies and concrete management tools should be implemented to maximize the internal impact of mobility activities, namely concerning the subsequent internal dissemination of key university values and innovative educational practices, as well as the support to internationalization at home initiatives. 
Evidence for this study was collected from one university in a single European country. However, the study has some international coverage, since the insights of incoming students and outgoing faculty were experienced in their countries of origin and in the receiving countries. Findings need further validation and additional evidence should be collected in future studies in other universities, namely in universities with distinct profiles, and from other countries. This is the main limitation of this study. It does not imply that the conclusions are invalid, but it implies that their completeness and universality cannot be assumed before further and more comprehensive studies are undertaken. Also, the qualitative approach adopted in this study can be complemented by the use of quantitative studies that will allow for further hypothesis testing on the identified propositions. These constitute the future directions of the research study.

\section{References}

Altbach, P.G. (1998) Comparative Higher education: Knowledge, the University, and Development, Westport: Ablex Publishing.

Altbach, P.G. (2004) 'Globalisation and the university: Myths and realities in an unequal world', Tertiary Education \& Management 10(1): 3-25.

Amendola, A. and Restaino, M. (2016) 'An evaluation study on students' international mobility experience’, Quality \& Quantity 51(2): 525-544. DOI: 10.1007/s11135-016-0421-3

Bañegil-Palacios, T. M. and Sánchez-Hernández, M. I. (2018) 'The Challenge to Foster Foreign Students'Experiences for Sustainable Higher Educational Institutions', Sustainability 10 (2): 495. DOI:10.3390/su10020495

Bauder, H. (2015) 'International doctoral students as knowledge brokers: reciprocity, trust and solidarity in transnational networks', Global Networks 15: 217-235.

DOI:10.1111/glob.12069

Bedenlier, S. and Zawacki-Richter, O. (2015) 'Internationalization of higher education and the impacts on academic faculty members', Research in Comparative and International Education 10(2): 185-201.

The Bologna Process Secretariat (n.d.) 'European Higher Education Area and Bologna Process' (online), viewed December 5, 2019. http://www.ehea.info/

Brooks, R. (2018) 'Understanding the higher education student in Europe: a comparative analysis', Compare: A Journal of Comparative and International Education 48(4): 500-517. DOI: 10.1080/03057925.2017.1318047

Brown, M., Boateng, E. A. and Evans, C. (2016) 'Should I stay or should I go? A systematic review of factors that influence healthcare students' decisions around study abroad programmes', Nurse Education Today 39: 63-71.

Cairns, D. (2018) 'Researching social inclusion in student mobility: methodological strategies in studying the Erasmus programme', International Journal of Research \& Method in Education 42(2): 137-147. DOI: 10.1080/1743727X.2018.1446928

Council of the European Union (2018) 'Council recommendation on promoting common values, inclusive education, and the European dimension of teaching', Official Journal of the European Union, C 195, 7 June.

Creswell, J.W. (2013) Research Design: Qualitative, Quantitative, and Mixed Method Approaches, Thousand Oaks: Sage publications.

Fava-de-Moraes, F. and Simon, I. (2000) 'Computer networks and the internationalization of higher education’, Higher Education Policy 13(3): 319-324. DOI: 10.1016/S09528733(00)00016-7

Giorgi, A. (1997) 'The theory, practice, and evaluation of phenomenological method as a qualitative research practice procedure', Journal of Phenomenological Psychology 28(2): 235-260. 
Graf, L., Powell, J.J.W., Fortwengel, J. and Bernhard, N. (2017) 'Integrating international student mobility in work-based higher education: The case of Germany', Journal of Studies in International Education 21(2): 156-169. DOI: 10.1177/1028315316687010

Gribble, C. (2008) 'Policy options for managing international student migration: The sending country's perspective', Higher Education Policy 30: 25-39. DOI: $10.1080 / 13600800701457830$

Harman, G. (2004) 'New directions in internationalizing higher education: Australias's development as an exporter of higher education services', Higher Education Policy 17: 101 120. DOI: $10.1057 /$ palgrave.hep. 8300044

Jacobone, V. and Moro, G. (2015) 'Evaluating the impact of the Erasmus programme: Skills and European identity', Assessment \& Evaluation in Higher Education 40(2): 309-328. DOI: 10.1080/02602938.2014.909005

Klemenčič, M., Žnidaršič, M., Vavpetič, A and Martinc, M. (2017) 'Erasmus students' involvement in quality enhancement of Erasmus+ mobility through digital ethnography and ErasmusShouts', Studies in Higher Education 42(5): 925-932. DOI:10.1080/03075079.2017.1293879

Knight, J. (2011) 'Five Myths about Internationalization', International Higher Education 62: 14-15. DOI: 10.6017/ihe.2011.62.8532

Leask, B. (2009) 'Using formal and informal curricula to improve interactions between home and international students', Journal of Studies in International Education 13(2): 205-221.

Llurda, E.L., Gallego-Balsà, C.B. and Martin-Rubió, X. (2016) 'Erasmus student mobility and the construction of European citizenship', The Language Learning Journal 44(3): 323-346.

Marczyk, G., DeMatteo, D. and Festinger, D. (2017) Essentials of research design and methodology, New Jersey: John Wiley.

Marginson, S. (2006) 'Dynamics of national and global competition in higher education', Higher Education 52: 1-39.

Martínez-Usarraldea, M-J., Pausá, J. M. and García-López, R. (2017) ‘The ERASMUS experience and its capacitating potential: Analysis of adaptive capabilities', International Journal of Educational Development 53: 101-109.

Messelink, A. and Tem Thije, J.D. (2012) 'Unity in super-diversity: European capacity and intercultural inquisitiveness of the Erasmus generation 2.0', Dutch Journal of Applied Linguistics 1(1): 80-101.

Messelink, H.E., Van Maele, J. and Spencer-Oatey , H. (2015) 'Intercultural competencies: What students in study and placement mobility should be learning', Intercultural Education 26(1): 62-72. DOI: 10.1080/14675986.2015.993555

Morley, L., Alexiadou, N., Garaz, S., González-Monteagudo, J. and Taba, M. (2018) 'Internationalisation and migrant academics: The hidden narratives of mobility', Higher Education 76(3): 537-554. DOI:10.1007/s10734-017-0224-z

Neave, G. (2002) 'Anything goes: Or, how the accommodation of Europe's universities to European integration integrates an inspiring number of contradictions', Tertiary Education \& Management 8(3): 181-197. DOI: 10.1080/13583883.2002.9967078

Organization for Economic Cooperation and Development (2017) Education at a Glance 2017: OECD Indicators, Paris: OECD Publishing. DOI: 10.1787/eag-2017-en

Osborne, J. W. (1994), 'Some similarities and differences among phenomenological and other methods of psychological qualitative research', Canadian Psychology 35: 167-189.

Rensburg, I., Motala, S. and David, S. A. (2015) 'Learning mobility and internationalisation of higher education: Economic and policy implications for BRICS nations', International 
Journal of Education Economics and Development 6(3): 262-278. DOI:10.1504/IJEED.2015.073164

Stromquist, N. P. (2007) 'Internationalization as a response to globalization: Radical shifts in university environments', Higher Education 53: 81-105. DOI 10.1007/s10734-005-1975-5

Teichler, U. (2004) 'The changing debate on internationalisation of higher education', Higher Education, 48: 5-26.

Wen, W., Hu, D. and Hao, J. (2016) 'International students' experiences in china: Does the planned reverse mobility work?', International Journal of Educational Development 61:204212. DOI: $10.1016 /$ j.ijedudev.2017.03.004

van der Wende, M.C. (2001) 'Internationalisation policies: about new trends and contrasting paradigms', Higher Education Policy 14(3): 249-259. DOI: 10.1016/S0952-8733(01)000186

de Wit, H. (2011) 'Internationalization of Higher Education: Nine Misconceptions', International Higher Education 64:6-7. DOI: 10.6017/ihe.2011.64.8556 